\title{
Market-Motivated Value Systems and Reverse Logistics : An Evaluation Model for Third Party Reverse Logistics Providers
}

\author{
Guojun Ji*
}

\begin{abstract}
The feasibility and desirability of reverse logistics in market-motivated contexts are examined in China. Interactions between the major barriers, that hinder or prevent the application of reverse logistics in China are analyzed. Management's key task is to diagnose barriers to the application of reverse logistics that could be crucial to the organization's future survival. Simultaneity, a value delivery system exists to create value for customers and environments by supplying needed products and services. Value delivery systems are at the heart of every firm and, more than anything else, determine that, whether the firm survives in the marketplace or disappears into bankruptcy or takeover. The processes and model of market-motivated reverse logistics value delivery system are discussed, and the processes content and model are presented. Simultaneity, based on the advantage of the Third Party Reverse Logistics Providers (3PRLs) and Outsourced Service Providers, an integrated evaluation model is built to select 3PRLs by using the integrated decision-making methods. Reflecting the comprehensive information requirement, the Analytic Hierarchy Process and entropy approaches are applied to calculate the objective weights. A new kind of relative similarity degree is established by combining the Euclidean distance with the grey correlation degree. An example demonstrates the model's efficiency.
\end{abstract}

Keywords: value delivery, reverse logistics, Third Party Reverse Logistics Providers

Submission Date: 1/20/2006 Acceptance Date: 5/22/2006

* Corresponding Author: Professor, School of Management, Xiamen University, Xiamen Fujian, 361005 China, E-mail: jiking@xmu.edu.cn 


\section{INTRODUCTION}

Rapidly globalizing markets, production and distribution systems operating within complex and fluid capital markets have triggered exceptional economic and competitive pressures in national economies. Consequent microeconomic reform, deregulation and the corporatization and privatization of national marketplaces have been no less significant and have further impacted on nation-wide, as well as international, global logistics systems so that change is now pervasive, urgent and transforming. For buyers of freight services, whether manufacturers, rural and primary producers or retail giants, the pressing need to control costs in supply chains has spawned numerous strategies within a broader supply chain management framework that seeks sophisticated levels of operational as well as corporate integration-and ideally, fully integrated corporate and intercorporate business processes. For sellers of freight services-traditional "transport" providers now best described as third party reverse logistics providers (3PRLs) and fourth party service providers (4PRLs). They provide the outsourcing service of reverse logistics to the companies, intervene between buyer or shipper and customer-the focus on value delivery in competitive markets and are underlying urgent attempts to expand control over freight activities and to capture an increased share of value over the entire movement chain. It is resulting in rapidly restructuring corporate and value delivery systems.

Therewith, over the last several years, changes in environmental laws and the new returns demands of market returns have raised the requirement for effective reverse logistics to a new level, reverse logistics issues are gaining justifiable popularity among society, governments and industry worldwide. They are mainly regulatory-driven in Europe, consumer-driven, market-driven and profit-driven in North America and in incipient stage in other parts of the world, including China, where both consumer awareness and globalization are likely to lead to greater economic, consumer and regulatory pressures in the coming future. Only very recently, some companies in consumer durables' and automobile sectors in China have introduced exchange offers to tap customers who already own such products. Presently, these returned products are either resold directly or after repair and refurbishment by firm franchisee/ local remanufacturers in the seconds' market. They are not remanufactured or upgraded by original equipment manufacturers (OEMs). In Chinese society is particularly price sensitive and to a little extent quality sensitive (quality for a given price) but not environment sensitive in its buying and promotion behavior in 
past years. Therefore, reverse logistics has not received the desired attention and is generally carried out by the unorganized sector for some recyclable materials such as paper and metal. Presently, with market economy bring to success gradually, only markets (driven by economy, environment, policy, health, etc.) are relevant in China as statutory regulations and consumer pressure are virtually non-existent. This provides a good opportunity to explore and examine market-motivated Reverse Logistics Network Design (RLND). Many products are returned to the retailers shortly after a consumer purchases the product, and as a result retailers have a large problem managing returns. As well, manufacturers must deal with returns from retailers, the channels of distribution, or end customers with warranty issues. For example in 2001 there were about 40 million desktops and mobile Personal Computers sold. About 9 million $(23 \%)$ of these were sold through retail stores. The retailer experienced a return rate of about $10 \%$ or 900,000 Units. Each of these units is estimated to cost the retailer $\$ 40-\$ 50$ to process and ship back to the manufacturer or to dispose of the units. The manufacturers estimate that each return costs them about $\$ 500$ each. This adds up to a whopping $\$ 486$ million. Each return is taking the manufacturers from 4 to 12 weeks to fully process. Returns are a small percentage of sales for the retailer or manufacturer, however, in high volume environments like consumer goods, this small percentage adds up to a large reverse logistics problem.

Our present work is motivated by increasing sales potential of white goods, pharmacy and automobiles and the good response exchange offers by OEMs or retailers have generated so far, for example, China Government has come on the automobile recall system from March 2004, and Guangdong Province has set up the overdue pharmacy recall mechanism from 2005. This leads to the requirement of setting up a proper RL system. A well-managed RL program can result in important cost savings in procurement, disposal, inventory holding and transportation. This may be carried out by the OEMs or their consortia or by 3PRLs.

With the global economy development, a remarkable phenomenon shows that the value delivery system exists to create value for customers and environments by supplying needed products and services. Value delivery systems and their abilities are at the heart of every firm and, more than anything else, determine whether the firm survives in the marketplace or disappear into bankruptcy or takeover. Value delivery systems may take many forms as illustrated by these two cases (Meredith and Shafer, 1999) as follows: (1) Facing increased competition and customers who are smarter, more demanding, and less brand-loyal, McDonald's is reevaluating the way it makes some of the items on its menu. For example, it is considering a switch to a hamburger 
bun that does not require toasting. In trial tests, customers seemed to prefer the new bun's taste and texture. Furthermore, not toasting buns should translate into substantial cost savings due to reduced preparation time and the elimination of commercial toasting equipment (Gibson, 1995). (2) It is not well known that the Kmart and Wal-Mart chains both date back to 1962 . By 1987 Kmart was clearly dominating the discount chain race, with almost twice as many stores and sales of \$25-\$63 billion to Wal-Mart's \$15.96 billion. However, for the retail year that ended in January 1991, Wal-Mart had overtaken Kmart, with sales of \$32.6 billion to Kmart's sales of \$29.7 billion. Interestingly, although Wal-Mart had taken the lead in sales in 1991, it still had fewer stores-1721 to Kmart's 2330. By the 1997 retail year, Wal-Mart had clearly established itself as the dominant discount chain, with sales of $\$ 106.1$ billion to Kmart's \$31.4 billion. For the period from 1987 to 1995 Kmart's market share declined from 34.5 percent to $22.7 \%$, while Wal-Mart's increased from $20.1 \%$ to $41.6 \%$. What accounts for this reversal in fortunes? Kmart's response to the competition from Wal-Mart was to build on its marketing and merchandising strengths and invest heavily in national television campaigns using high-profile spokespeople such as Jaclyn Smith. Wal-Mart took an entirely different approach and invested millions of dollars in value delivery systems for the products it sells in an effort to lower costs. For example, Wal-Mart developed a company-wide computer system to link information from cash registers to firms in its supply chain, thus greatly facilitating inventory management. The integration of the system and the distribution system meant that customers would rarely encounter out-of-stock items. Further, the use of scanners at the checkout stations eliminated the need for price checks. By Kmart's own admission, its employees were seriously lacking the skills needed to plan and control inventory effectively (Duff and Ortega, 1995).

These brief examples highlight the diversity and importance of value delivery systems. Great many societal changes inevitably involve in value delivery systems. There is great pressure among competing nations to increase national productivity. Businesses are on a national crusade to improve quality and speed of their offerings in both products and services. As we will see, increasing productivity of the firm and adding value to customers and environments are primary objectives of market-motivated reverse logistics value delivery systems.

Otherwise, technological change is an important consideration. Technologies such as e-mail, laptops, personal digital assistants, e-commerce, are profoundly affecting business and are fundamentally changing the nature of today's work. Many banks are shifting their focus from building new branch locations to using the Web as a way to 
develop new customer relationships and transaction processes. Banks rely on technology to carry out more routine activities as well, such as transferring funds instantly across cities, states, and oceans. Other industries also rely increasingly on technology for efficient, effective and secure processes, e.g., global positioning systems to monitor logistics activities, electronic data interchange and collective supply-chain adoption of the same server of database and planning systems.

In this paper, the feasibility and desirability of reverse logistics in market-motivated contexts are examined based on the China current in this paper. The interactions among the major barriers, which hinder or prevent the application of reverse logistics in China industries were analyzed. The processes and model of market-motivated value delivery systems based on reverse logistics are discussed, and the process content and model are presented. Consider the advantage of 3PRLs and outsourced service providers, an integrated evaluation model was built to select the three reverse logistics service providers using by the integrating decision-making methods in this paper. To reflect the comprehensive information, the Analytic Hierarchy Process and entropy approaches are applied to calculate the objective weights. A new kind of correlation similarity degree was established by combining the Euclidean distance with the grey correlation degree (that denotes correlative factors relation presented by grey numbers). In the end, an example was demonstrated our conclusions.

\section{DEFINITIONS EXPATIATION}

Reverse logistics (RL) is the collective noun for logistic environments with reuse of products, work in process and materials. Possible cost reductions, more rigid environmental legislations, and increasing environmental concerns of consumers have led to increasing attention to reverse logistics in the recent years. Reverse Logistics provided by RevLog a European Reverse Logistics initiative: “... Reverse Logistics though refers to all activities to collect, disassemble and process used products, product parts, and/or materials in order to ensure a sustainable (environmentally friendly) recovery." Reverse logistics activities include: Processing returned merchandise for reasons such as damage, seasonal, restock, salvage, recall, or excess inventory; Recycling packaging materials and reusing containers; Reconditioning, remanufacturing and refurbishing products; Obsolete equipment disposition; Hazardous material programs; Asset recovery. 
Figure 1 shows the basic flow diagram of reverse logistics activities. The complexity of operations and the value recovered increase from bottom-left to top-right in the figure.

Figure1. Flow Diagram of Reverse Logistics Activities

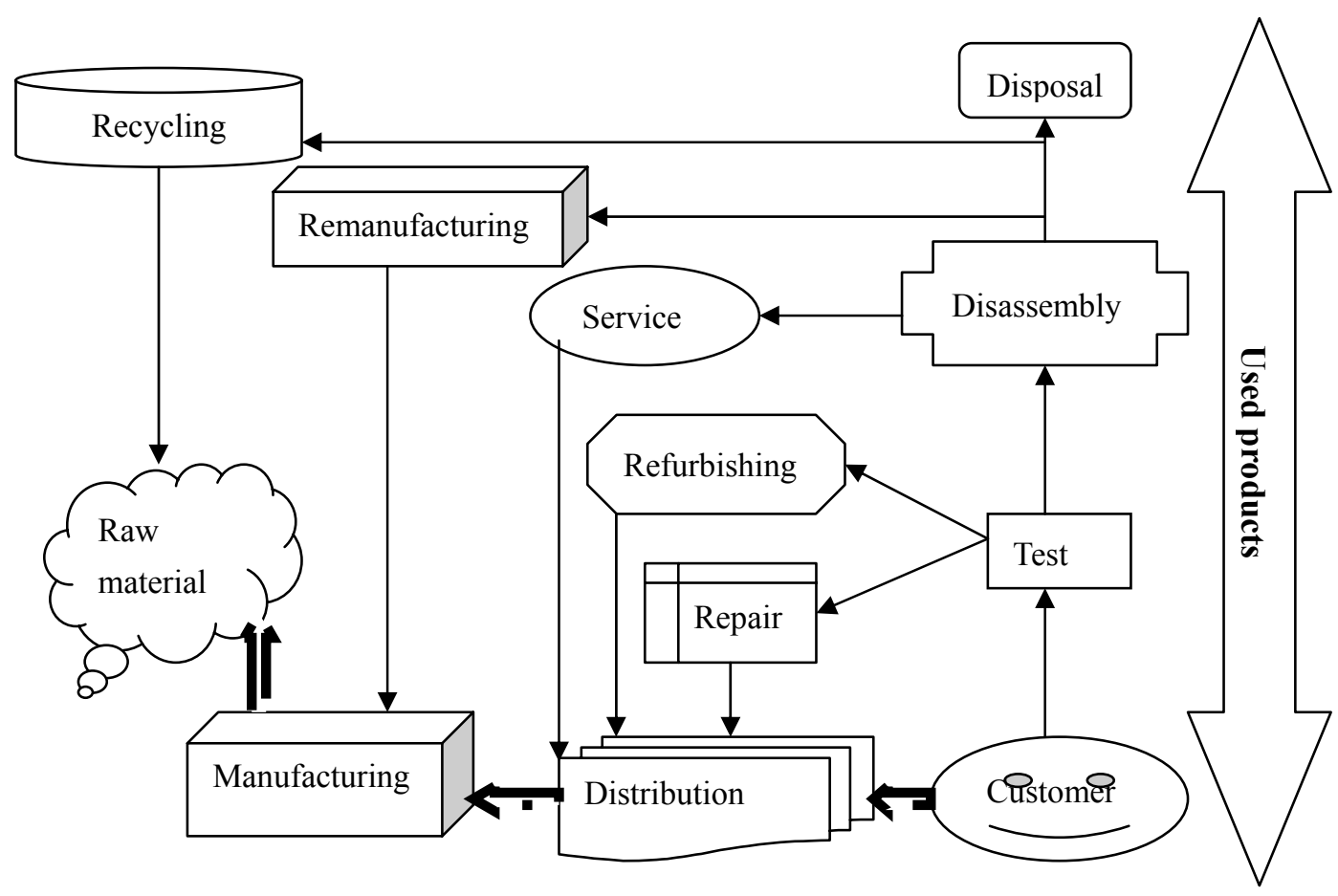

Source: Krumwiede and Sheu (2002)

RL comprises network design with aspects of product acquisition and remanufacturing (Fleisch mann et al., 2001). Literature suggests that the pattern of quantity, quality and time of arrival of returns is of paramount importance in reverse logistics network design. The location of facilities relative to process inputs, customer markets or waste disposal locations has been considered both analytically and empirically (Appa and Giannikos, 1994; Froch, 1995; Pushchak and Rocha, 1998). Strictly speaking, competition, value delivering and marketing motives, direct economic motives and concerns with the environment are some of the important of them. Literature describes four important stages in RL. Collection is the first and an important stage, where product types are selected and products are located, collected, and, if required, transported to facilities for rework and remanufacturing. Used 
products originate from multiple sources and are brought to a product recovery facility, resulting in a converging process. Inspection/ Sorting is the next stage which may be carried out either at the point/ time of collection itself or afterwards (at collection points or at rework facilities). This may or may not be combined with pre-processing. Pre-processing may cover in the form of sorting, segregation, partial or complete disassembly or minor repair and refurbishing activities. It may be carried out either at collection centers or at rework facility depending upon various technological and economic factors.

Location and distribution (network design) is the most important and critical stage of reverse logistics that is assuming greater importance in business as well as in theory (Tibben-Lembke and Rogers, 2002). In many cases, recovery networks are not set up independently "from temporary" but are often combined with the existing logistics structures. In particular, this is true if products are recovered by the OEM. Location and configuration of facilities frequently affect and are affected by the external natural environment, mainly the estimated returns. Redesigning logistics networks to accommodate product returns and remanufacturing and reuse of such parts and components can often be quite profitable are remarked (Corbett and Kleidorfer, 2001).

\section{EXISTING BARRIERS, THE RETURNS PROCESS, RESEARCH ISSUES AND GAPS}

\subsection{Existing Barriers}

Despite the fact that practices related to reverse logistics have helped the cause of environment protection, practicing the much-needed approaches is not free from barriers. In this paper, eight existing barriers to the reverse logistics have been selected from the literature primarily from Rogers et al. (1998) and also from discussions with experts in the automobile industry, synthesizing the China automotive industry. These barriers are explained as follows.

\section{Lack of comprehension}

A chief barrier of reverse logistics seen in China is lack of comprehension about the benefits of reverse logistics. Even if companies clear about it, giving relative unimportance to reverse logistics was seen as the largest barrier to reverse logistics, because there are some companies only consider self-regard or are eager for quick success and instant benefit. Firms are finding in a position irrespective of whatever industry they are, whether automobile, food processing, or paper industry, there is an 
increasing case of product recalls. Today, many consumer products have a shorter life cycle, for example, mobile telephone. While the customers have the benefits of greater product variety, it has resulted in an increase in unsold products, rate of returns, packing materials, and also the waste (Van Hoek, 1999). This has given rise to increase in the volume of product returns in the form of reverse logistics. Therefore, the management of parts or product coming back into the supply chain network from its outbound side is a matter of concern for many industries (Guintini and Andel, 1995). The reverse logistics can lead to economic values by the recovery of the returned products for reuse, remanufacturing, recycling, or a combination of these options for adding value to the product. The implementation of the reverse logistics leads to direct benefits to the environment and society, too. Thus, the lack of the comprehension of these values is a major barrier to reverse logistics.

\section{Lack of information and technological systems}

A very serious problem faced by the firms in the implementation of reverse logistics is the lack of good information systems, specially, for Medium and small enterprises in China. An efficient information and technological system is very necessary for supporting the reverse logistics during various stages of the product life cycle. During the product development process, the important facts to be considered are the raw material content and the product structure. The type and quality of the materials and the technology used for manufacturing determine the extent of the product recovery that is possible influencing on the end-of-use/end-of-life of the product. Excellent IT systems can be very useful for the product development programs encompassing the design for the environment, recovery, reuse, and so on. Efficient information systems may redound to individually tracking and tracing the returns of the product, linking with the previous sales. Relating the product return with a past market sale can support forecasting of product returns, thus improving inventory management (de Brito et al.,2002). It can be very useful for the planning and control of the product recovery activities. Information support is necessary for developing linkages to achieve efficient reverse logistics operations (Daugherty et al., 2002). A concept of "virtual warehousing" where real-time information feeds expeditious algorithms to support decisions for tracking component's order in the case of a closed-loop business telephones supply chain was represented in Landers et al. (2000). The case of Xerox where bar code labels were used to track packaging material with the aim of achieving resources preservation was discussed (Maslennikova and Foley, 2000). The use of information and new technologies to improve processes in the reverse chain for the 
situation where products and equipment need to be disassembled was analyzed in Mok et al. (1997). Recently, even if logistics industries develop rapidly in China, very few firms have successfully applied in IT system or automated the information surrounding the returns process. Although it is reported that more than $77 \%$ large-scale companies applied some IT systems, most of them just adopt part function so much as it is not perfect (Storage Institute, 2005). Say nothing of a lack of good reverse logistics information management systems commercially available. Thus, IT system is a very significant barrier affecting good reverse logistics.

\section{Company strategies}

Restrictive company strategies are an important barrier to the reverse logistics operation. Most companies make profit as their uppermost objective, the lack of the important attention of the reverse logistics and the management inattention are related to the strategies followed by the companies. Companies are willing to invest a great deal capital to create a brand image to the customers. They do not want to compromise on the end-product quality by using the returned products. Thus, the strategies constituted by companies of producing only virgin products also have a major effect of not handling the returned products and to recover the secondary value-motivated from the returns. Since the advent of extended producer responsibility (Lindhgvist, 2000), many companies have started to integrate the recovery options for the products into their supply chain. There seems to be a paradigm shift by the companies to change their rigid strategies to incorporate the returns of the product to recover value economically that could give them edge over their competitors.

Reverse logistics can be used as a strategic weapon in the present industrial environment (Rogers and Tebben-Lembke, 1998). Strategic planning is the identification of reverse logistics goals and the specification of long-term plans for managing them. It involves the attempt on the part of the manager on the course of action that has to be adopted for the realization of reverse logistics. In the present scenario, a well logistics program is important for the enterprise's strategy, a sound strategic planning is necessitated for the reverse logistics programs. From the market-motivated value, for implementation of reverse logistics in any organization, the role of strategic planning is very important to achieve the goals for the survival of the organization in the global market.

\section{Problems with product quality}

Another important barrier affecting reverse logistics is the fact of the quality of the 
end-of-use/end-of-life returned products. The product quality is not often uniform in reverse logistics compared to the forward logistics where the product quality is uniform (Tibben-Lembke and Rogers, 2002). The overall quality targets for remanufactured/recycled products must be, at the least, equivalent to the virgin products (Thierry et al., 1995). Customers usually expect the same level of quality of product from the manufacturer regardless of the nature of the returned product. When the returned products arrive at the distribution center, a decision must be made for its disposition. Gatekeeping, which is a process of screening of the defective and unwarranted returned products at the entry point into the reverse logistics, is a very critical factor in realizing the entire reverse flow manageable and profitable. The returned product quality could be in any range; like that it could be faulty, damaged, or simply unwanted by the customer. Thus, there could be variations in the pricing of the products. The prices of the products in the forward channel could vary due to a lot of the factors like the quantity of the products purchased. The quality of the returned products is inspected by gatekeeping and a decision is then made to the disposition of the product. Thus, in the case of the returned product, the pricing can be more difficult compared to the forward logistics.

\section{Resistance}

Another key barrier in the implementation of the reverse logistics is the resistance to transform or implementation, human nature often being a fundamental barrier. Expressly, managers usually pay more attention on profit and cost. People avoid change when once possible, and the reverse logistics require a radical change in the mindset and practice. Especially, in the case for small business with limited capital to influence contracts with suppliers, the problem becomes very serious. In this instance, the company strategies and organizational structures get standpat rather than facilitate change. Some companies argue against reverse logistics vision, even only regard "making money" from wasting nature resources. For example, some lawless collieries are distributed in the remote mountainous areas in China, mine stealthily without Government's permission. With increased global competition in the market and shrinking profit margins, companies are increasingly interested in savings derived from the recovery of used products. Most importantly, the adoption of the reverse logistics practices results in direct benefits to the environment and resources. The lack of awareness of benefits of the reverse logistics both from economic and environment angles could be a major factor for the resistance to change to reverse logistics. Reverse logistics systems initially involve high economic 
investment. Financial constraints and citizen consciousness could also lead to resistance to change to reverse logistics.

\section{Financial constraints}

Financial constraints are an important barrier to good reverse logistics operation. Cost considerations are a prime challenge in commercial recycling (WSRA, 2001). Finance is essential to support the infrastructure and manpower requirements of reverse logistics. Companies require allocation of funds and other resources for the implementation of reverse logistics. Efficient IT systems are significant enabler for reverse logistics. IT systems often require more funds because just with these, the returns product tracking and tracing and product recovery by various processes like reuse, remanufacturing and recycling become possible in the information environment. The training of personnel related to the reverse logistics is also very important for efficiently managing and eventually making the reverse logistics profitable. Clearly, all these require financial support.

\section{Lack of specialized training and education}

A significant barrier to good reverse logistics is a lack of manpower resources. Not only lack of specialized logistical personnel is a bottleneck to logistics development, but also lack of training and education is a major challenge to commercial recycling in China. Education and training are prime requirements for achieving success in any organization. The need for training on reverse logistics extends throughout the company and reaches up and downstream. Modern or revamped technology necessitates change and the personnel should be given adequate training in the new technology and processes that will be implemented. The training should be provided in critical business functions like product development, customer-driven management and resource management, so as which gives rise to new development opportunities to improve integration of environmental issues.

\section{Reluctance of the support of dealers, distributors, retailers and 3PLs or 4PLs}

Another important barrier to reverse logistics is the reluctance of dealers, distributors, and retailers to support reverse logistics activities. A generous return policy leads to improved risk sharing between sellers and customers. A liberal returns policy can lead to the customers returning the product in any form to the retailers, suppliers and manufacturers. Indeed, the liberal returns policy occasionally turns into "Return abuse" policies(Rogers and Tibben-Lembke, 1998). 
It is time to rethink Returns. Reverse Logistics is an excellent strategic source of value added revenues. Even if some of manufacturers, distributors and retailers are struggling with the reverse supply chain, and the industry experts suggest that the annual costs of reverse logistics total $\$ 35$ billion. In fact, product returns handling is an important process of the supply chain that is not well handled. Economic pressures for corporate profits are forcing manufacturers and retailers to look very hard at cost monitoring. Reverse logistics is one of the few remaining opportunities that have not yet received much attention.

In other circumstances, 3PRLs and 4PRLs intervene in firm-to-firm transactions to effect value delivery. In recently years, many manufacturers and retailers are looking to outsource reverse logistics and product returns since it is not a strategic part of their business. They currently have very inefficient, slow and expensive processes for handling returns. Few tools or systems exist to assist in handling returns effectively. Considerable value is lost when these returned assets are not processed quickly and completely. 3PRLs and outsourced service providers are ideally suited to manage reverse logistics since the specialization skill sets used to process forward and reverse logistics are similar. Reverse logistics, however, encompasses much more than accepting inbound shipments from your client's customers.

Traditionally, product returns are something that 3PL's try to avoid. However, with a solid understanding of reverse logistics needs and processing, reverse logistics represents a quick and excellent source of high volume transaction fees that can be generated from your existing facilities and skill sets. As companies strive to wring every cent out of their logistics costs, they are increasingly taking a hard look at their reverse logistics practices. And no wonder - they may find a mother lode waiting to be mined. Reverse logistics services are an opportunity for outsource providers to: Provide additional services for new revenues from your existing customers; Differentiate your company's services from those of your competitors; Attract new clients to these services; Enhance your status in the global supply chain.

\subsection{Returns processes}

The Returns processes can be summarized in the Figure 2 as follows. In processing a returned unit, two groups need to be satisfied: the end customer who returned the unit and the company that now needs to handle the returned unit and try to recapture value from it. 
Figure 2. Returns Processes be summarized

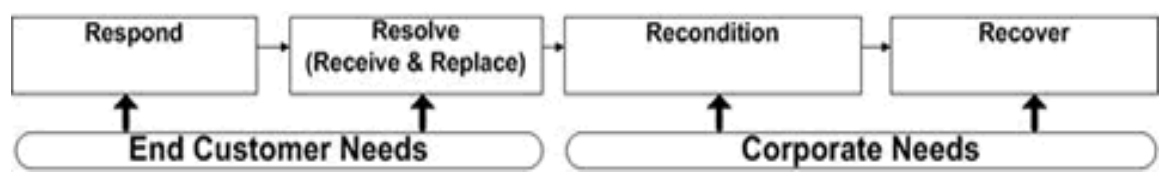

An overview of the returns process is as follows:

Retailers: Retailers need to handle returns from their customers. These returns arrive in a variety of conditions, many with open boxes, some with defective units and many with no faults. A retailer needs to process these returns and maximize value from these returned items by getting them back on the store shelf, returning them to the manufacturer for credit, liquidating them through some other channel or scrapping them.

Manufacturers: Manufacturers need to handle returns from multiple sources such as end-user customers, retailers, value added resellers or distributors. The manufacturers typically require their customers to obtain an approved returned materials authorization (RMA) or return authorization (RA) before accepting any product returns. These returns arrive in various quantities. The returns may be new stock, damaged stock, open box or defective. The manufacturer's main concern is to satisfy the customer or distribution channel partner who is returning the goods by exchanging the unit, repairing the unit or issuing a credit. The returned units need to be processed and then returned to inventory, repackaged, returned to vendor, repaired or scrapped. The manufacturer needs to maximize value on these returned units by processing them quickly to yield the highest price through secondary market channels.

\subsection{Research Issues and Gaps}

There is generally a structural difference in cost drivers between RL and forward logistics (FL) networks as it is relatively more difficult to predict/ estimate RL costs. The dimensions used to characterize the RL environments are: returns volume, returns timing, returns quality (grade), product complexity, testing and evaluation complexity and remanufacturing complexity (Guide et al., 2003). Return timing concerns how much time elapses between the sale of the item and the return of the item to a collection centre. Besides, product volumes, probability of returns, procurement delays and average product life cycle greatly impact the return streams along the reverse supply chain. These uncertainties in supply are an additional concern not usually faced 
in planning for forward flows.

There is little scientific literature on the empirical analysis of data with reverse flows (de Brito and Dekker, 2003). Coupled with the rapidly increasing return volumes, the complexity of return logistics becomes problematically complex. Meade and Sarkis (2002) suggest that a reverse logistics chain that depends on product life cycle, industry and design of reverse logistics network needs to be available for customer service. Besides, there is little literature that covers both the remanufacturing and RL aspects of green supply chain in an integrated manner. This offers tremendous business and research opportunities for reverse logistics.

\section{THE VALUE DELIVERY SYSTEM AND ITS PROCESSES BASED ON REVERSE LOGISTICS}

\subsection{Value Delivery System}

Why are the value delivery systems considered to be the heart of every firm? Fundamentally, firms exist to create value, and value delivery systems based on reverse logistics serve as the vehicle to create that value. Regardless of whether the firm is for-profit or not-for-profit, primarily service or manufacturing, public or private, it exists to create value. Thus, nonprofit organizations like the Red Cross strive to create value for the recipients of their services. Generally, a value delivery system supplies a family of return products or services to manufacturers or recall centers (such as 3PRLs). A firm may have value delivery systems for different aims, and the value channels show bi-orientation. Traditional Supply Chain improvement strategies have tended to focus on forward logistics processes. New forces, and an understanding of the connection to revenue and customer satisfaction and environment, are moving reverse logistics higher in the supply chain agenda. Therefore, in practice, such value delivery systems are also called closed-loop systems and bi-orientation value delivery system. Considering return processes, the activities involve in supply chain show in following Figure 3.

Figure 3. Activities involve in supply chain

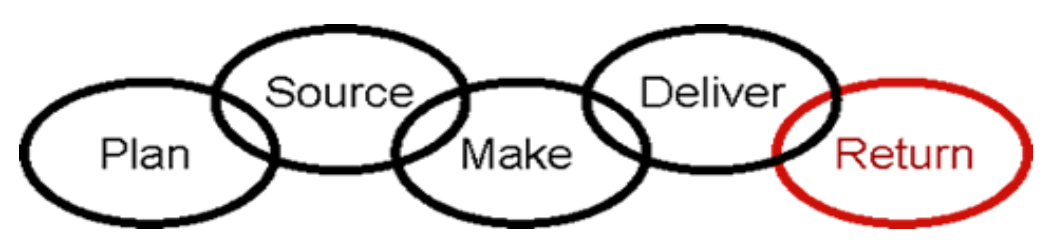


A value delivery system based on reverse logistics consists of a set of distinct processes. In turn, each process takes inputs or outputs and transforms them through a series of activities into useful outputs, such as returned materials, or intermediate products or services within the value delivery systems. Throughout many people use the terms 'process' and 'business process' interchangeably to describe specific aspects of a value delivery system. Using the previous example, the university could be viewed as the firm, the school of management as a business unit within the firm, each program or students' contribution as a different value delivery system serving its own target orientation, and each course within the program or student contribution to school as a process within the value delivery system.

Consider some other examples of value delivery systems: (1) An automobile assembly plant receives raw materials from its suppliers in the form of parts and components. These materials along with labor, equipment, information and energy are transformed within various assembly processes (e.g., frame assembly, body assembly, painting and seat assembly) into the output, automobiles, at the same time, companies and suppliers have a plan and make good decisions to get value out of returns, i.e., reverse orientation delivery. (2) A hospital is another organization with a service output. Here equipment, labor, and materia medica are applied to another input, the patient, through a serious of processes (admitting, testing, surgery, prescriptions, counseling, etc.) in order to transform him or her into a healthier or more comfortable person, and pharmacy or suppliers recycle materia medica from recovery.

\subsection{Market-motivated value delivery systems based on reverse logistics-the Missing Element in Business Strategy}

The term operations is often applied loosely in business, and can mean anything from a firm's facility, to a value delivery system, to a process, to an activity, to a formal functional organization of people. Recall that a value delivery system's definition, clearly, some of these processes are officially part of the operations functions, but there are likely other processes in a value delivery system that fall under other functional areas within the organization and within other organizations in the supply chain. For instance, we may view General Motors' Cadillac line as a value delivery system that includes assembly processes as well as processes in marketing, research and development, engineering and finance within its organization, and once their products are found the quality problems, they will operate recalling processes. Examples within GM include: (1) Marketing processes that introduce to customers the new season's Cadillac configuration; (2) Design processes responsible for engineering detailed 
features for that configuration; (3) Assembly and test processes within operations; (4) Sales processes responsible for finished good distribution, demand forecasting and promotions, and (5) recall processes responsible for reverse logistics activities.

Unfortunately, most firms manage processes departmentally, without recognition and concern for the entire value delivery system. The history and reasons for broken processes so prevalent in businesses today are explained (Harrington, 1991). A value delivery system and its associated processes were first developed out of a need to provide a family of products or services. In most companies, these needs logistics (contain the forward logistics and reverse logistics design) arose when the business was young and growing. They were developed quickly to meet an immediate need to marshal a small internal population to serve a small customer target base. After that meager beginning, the processes were neglected and ignored. They were not updated to keep pace with the business environment. No one took the time to review and refine those activities.

As business grew, disparate new products and services were added, but most likely provided by the same processes. Responsibility for these processes was divided among many departments, and additional checks and balances were instituted as small empires grew. Little pools of bureaucracy began to develop. Two, three, or even four replaced one signature. Bureaucracy became the rule rather than the exception. Patches were put on top of patches. No one really understood what was going on, so no one could audit business processes within value delivery systems to ensure that they were operating correctly. Along the way, the focus on the external customer was lost. The firm became more inwardly focused, and people did not really understand the impact of their activities on external customers.

Consequently, many business processes became ineffective, out of date, overly complicated, burdened with bureaucracy, labor intensive, time consuming, customer complaining, and irritating to management and employees alike. While most firms accepted these processes as a necessary evil, they have turned out to be millstones around the organization's neck that increasingly hamper its ability to compete. Harrington (1991) has reported that between 40 and 70 percent of all white-collar support effort in manufacturing add no value to customers. Eliminating white-collar errors and bureaucracy can cut overhead costs by as much as $50 \%$, make a firm a leader in its field, and greatly improve response time, quality and cost of products to customers.

It is no wonder that in practice, important decisions made by a firm bear little or no relationship to their stated or official business strategy-even if the firm regularly 
conducts what it considers a rigorous strategic planning exercise. One important reason is that firms tend to seek strategies that are uniform in nature. This offers apparent clarity in the form of consistent strategic statements that are easy to express, explain, and address. A desired level of uniformity has inherent attractions no matter what the company's scale. It is not surprising then that typical expressions of corporate strategy include such general terms as low cost, differentiation, balanced scorecard, green design, and critical success factors. The use of general terms such as these blur rather than focus the firm on differences in markets or activities that are increasingly characterized by difference, not similarity, and it brings conflicting demands on the operations function.

Unless strategy statements translate into actions and result in incremental or radical improvement in the value delivery systems, they are of little value. Markets are characterized by increasing difference, and often are closely linked environment, just as return processes emerge from the ordinary logistics. Companies replace annually some $10 \%$ of existing revenue with "better" margin business (Hill, 2000). The key to understanding market-motivated value, therefore, lies in being able to identify and integrate those new businesses into existing or new value delivery systems. Because the needs of the market segments differ, decision priorities likely differ by market segment and value delivery system. A clear and accurate understanding of a company's markets arises from facts, data and ongoing discussions of strategic options involving all functions and process stakeholders within value delivery systems. Firms must stop thinking functionally, and start thinking about markets served, and the value delivery systems and associated processes that need improvement, it is certain processes from the forward logistics to the reverse logistics is the inevitability of the global economy. World-class firms continuously strive to provide superior products and services to their target customers. For instance, NOKIA has made great efforts to recycle old mobile phone from 2002 in China. Now, we will discuss the business process improvement steps. The general approach advocated in this paper is called logistics process improvement, i.e., considering market-motivated value system based on reverse logistics. It provides an objective method for segmenting markets, uncovering customer and environment needs and developing a means to profitably satisfy those needs through the innovation or improvement of critical processes. The process improvement embodies the following principles: (1) Linking improvement efforts to the needs of target customers and environments, ensuring constancy of the global continuing development purpose; (2) Working on a manageable number of projects, emphasizing improvements to critical processes within value streams with the greatest 
potential for improvement and profit, since the reverse logistics is the universal demand; (3) Using facts, not speculation, based largely on long-term, healthy and saving inferred from customers and other stakeholders for selection and direction of improvement projects; (4) Pro-actively considering innovation and improvement, as well as forward logistics correction.

Business processes considering reverse logistics improvement efforts may well involve and impact people and their environment among society and every functional department in the value delivery system. It is therefore time consuming and ongoing. The process improvement initiative should be directed to a specific target market based on the viewpoints of profit, cost, resource and environment, its value delivery system and critical processes. It involves three basic steps:

\section{(S1) Determine the process intent}

Process intent is a clear statement of what the value delivery system is intended to do-create value of customers and environment, of course, but specifically who is the customer, how is the environment, what type of value is needed, and by how much additional value ( $\mathrm{Ji}, 2005)$.

Unmet needs continually arise between what customers require and polluted environments produced by production and what the firm currently delivers, and these needs may be expressed in general terms, e.g., missing or inferior aspects of the bundle of products/services that comprise the offering, a price too high relative to perceived value in the marketplace, or some shortcoming concerning response time in delivering the offering, harming and destroying behaviors of the worldwide ecosystem. If the firm expects loyalty from its customers and environments, these needs must somehow be satisfied by the firm's value delivery system and associated business processes. Thus, to improve the value delivery system, it is essential to first understand exactly who the customers are (target market profiles) and what they need, how we economize resources fully and be propitious to our living earth. Expressed needs or latent needs of customers and environments may be uncovered in various ways. It is important to understand not only the unmet customer needs but also the importance of each need, since the firm should focus its limited resources on satisfying the most important ones.

\section{(S2) Develop the process model}

A process model is a detailed statement of how work should be divided in the value delivery system to satisfy the process intent (the process model would be best labeled the "value delivery system model"). In fact, there are no universally optimal ways to 
organize work, but there is one way to organize work to satisfy the particular process intent. Unmet customer needs can be satisfied through development or improvement of one or more processes within the value delivery system, the processes orientations may cover not only forward but also backward. Critical processes in the value delivery system must be identified and understood. If critical processes already exist they should be dissected to uncover opportunities for improvement. Regardless of whether or not a process currently exists, it is important to benchmark other firms with similar processes that are considered world-class to discover their best practices. With this analysis, a process model which best conforms to the process intent may then be constructed.

\section{(S3) Establish the learning and improvement system}

The abovementioned covers how to establish continual learning and improvement within the "process model". Learning and improvement involves four sides: (1) Organization and management of change. The process model analysis conducted in S2 above should yield a set of actionable, prioritized recommendations as to how to profitably achieve the "ideal-state" in the value delivery system. Implementation of these process improvements requires effective organization and management. (2) Feedback and control. This entails monitoring progress of the the process improvement endeavor against the performance targets, and taking corrective action if necessary. Feedback and control should occur during implementation and after implementation during execution. (3) Standardization. It is important to document standard work practices established in process improvement efforts and communicate the knowledge gained to other parts of the business. Furthermore, process improvement on one aspect of the business may have been unsuccessful, yet the firm may have gained if the lessons can be shared elsewhere. (4) Holistic development views. Under the global economy, the company activities extend to the widest scopes, customers, environment, resources and society develop harmoniously.

\subsection{Process Intent}

Process intent (is commonly known in marketing circles as a value proposition)is a clear statement of what the value delivery system is intended to do, a strategic direction for the firm's management and employees as well as position statement for target customers and environments on the role of the value delivery system. According to Hill (2000), clear process intent rarely occurs in practice, and unclear process intent causes confusion for customers, managers and employees. Many companies mistakenly assume that particular products or services compete in the same way in different markets, thus, failing to 
recognize how business is won, for example, the design for reverse logistics is often different ways between the products of mobile phones and materia medica.

In today's competitive markets, customers and potential customers demand increased value from the firm's offerings. Unmet needs and reverse logistics needs are gaps that arise among what customers require, ecosystem protects and what the firm delivers. If the firm expects loyalty from its customers and the interrelated environments, these needs must somehow be satisfied by its value delivery system. To improve the value delivery system, it is essential to first understand exactly who the target customers are, what they need, how much they are willing to pay to satisfy this need, what they are handling product return, and what the impact will be on sales and profits and ecosystem. A firm must understand the importance of each need and focus its limited resources on fulfilling the most important ones. There must be a means to translate needs as customers express them into company language. That is, the external process intent must be translated into the internal process intent. Internal process intent relies on performance characteristics, design specifications and performance measures, and performance targets to describe the unmet needs in terms the company can measure. Figure 4 shows some steps involved in preparing the process intent.

\subsection{Process Model}

A process model is a detailed statement of how work should be divided to satisfy the process intent. Figure 5 shows a logical set of steps in developing a process model. The first is to construct a process map that identifies major processes within the value delivery system. Second, critical processes are identified whose innovation or improvement would enable us to satisfy the process intent. Processes should be dissected and analyzed to uncover opportunities for improvement. We do this using a lean audit and process benchmarking. A lean audit looks internally at existing processes, while process benchmarking looks externally at existing processes or ones that need to be created. In addition to a statement of the process model, it is also important to establish within the process model a set of actionable, prioritized recommendations as to how to achieve the process intent in a profitable manner and stay there. 
Figure 4. Preparation of process intent

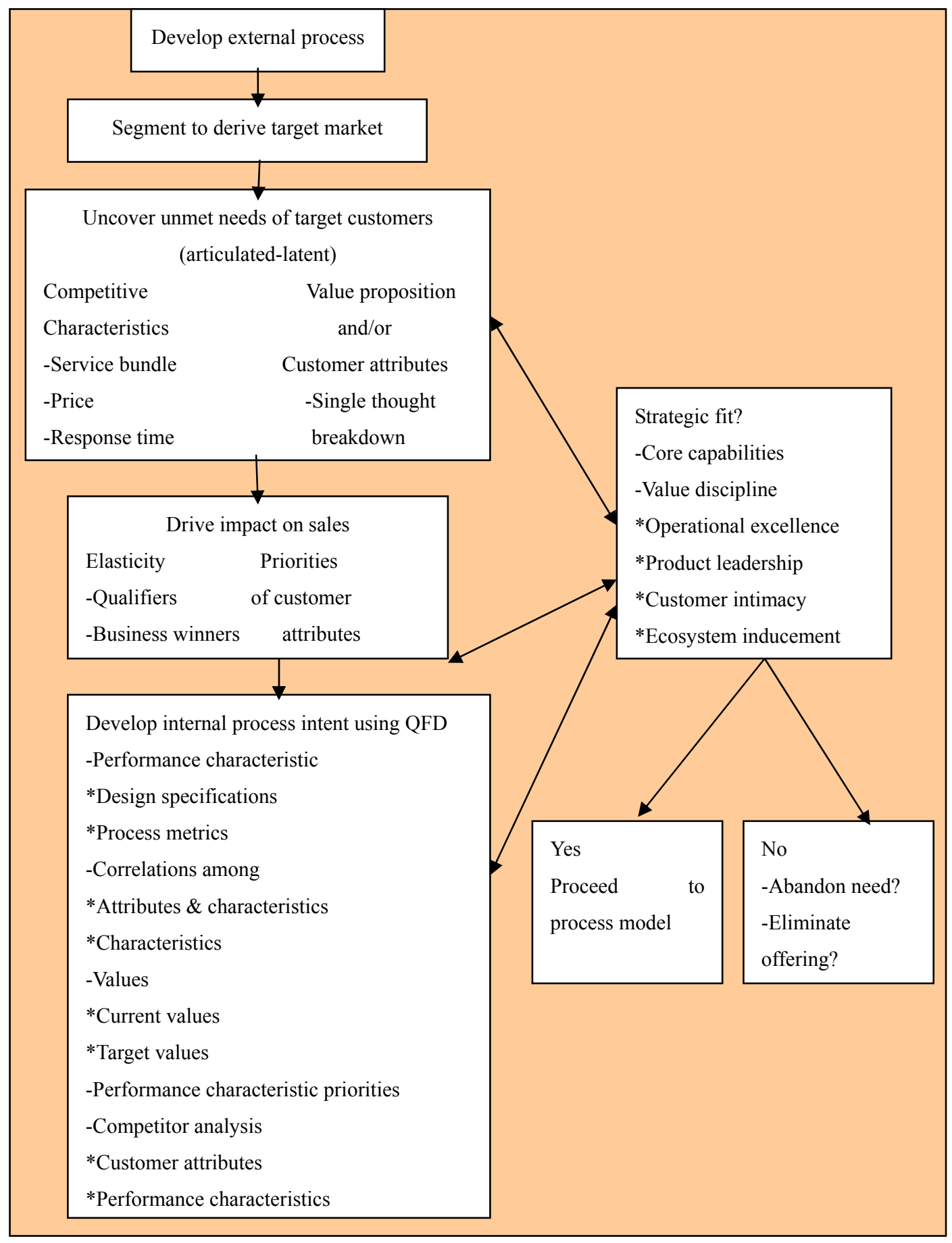


Figure 5. Development of process model

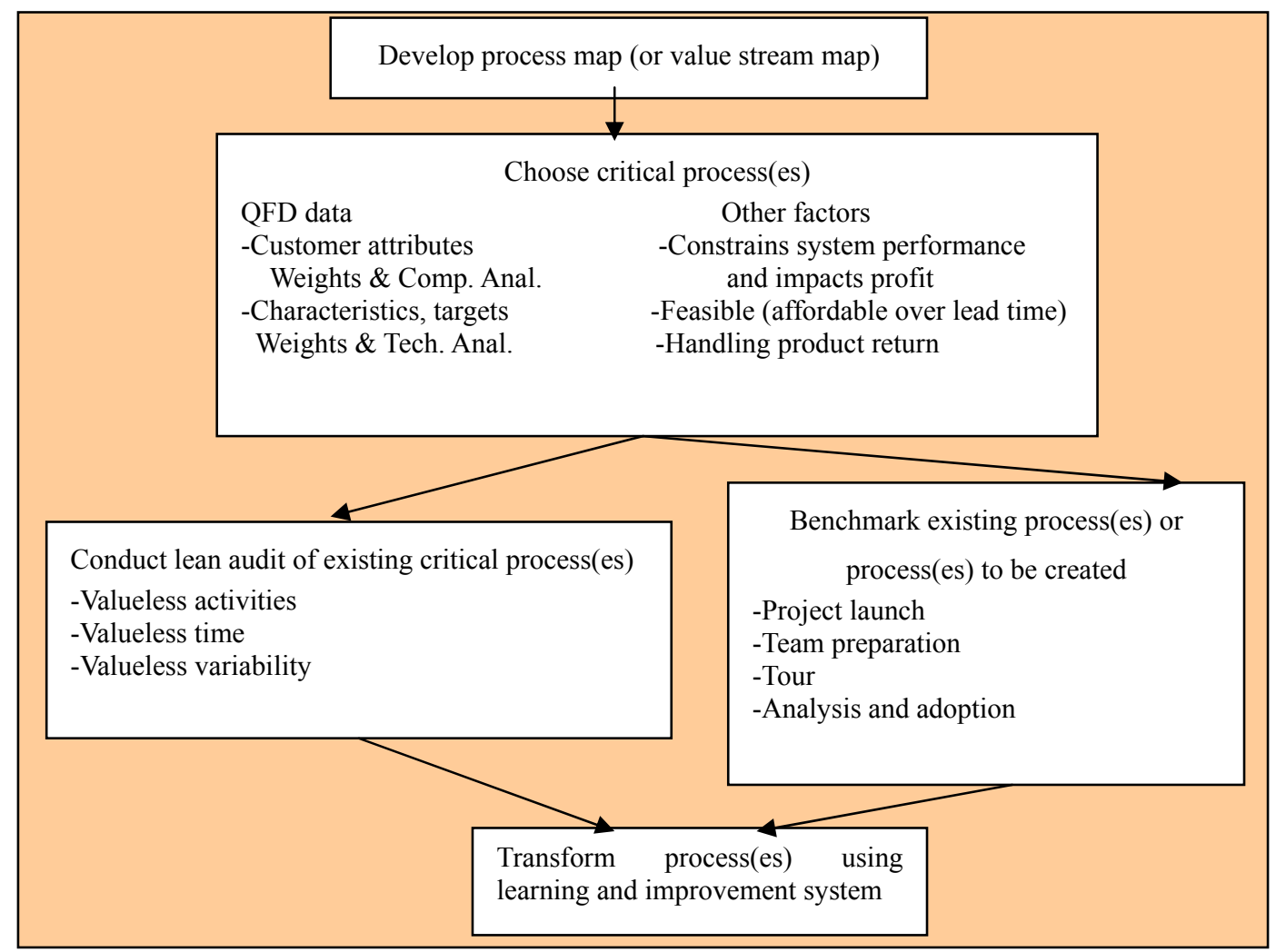

\section{OUTSOURCE PRODUCT RETURNS}

Currently most retailers and manufacturers struggle with handling and processing returns internally. Many manufacturers will conclude that handling product returns is not a strategic core competency and will look for an outsourced provider, as they have done with forward logistics. Most retailers and manufacturers struggle with returns for many reasons such as: It is a small part of their business processes; Their prime focus is on getting new products to customers; They have difficulty understanding and monitoring costs; There is poor or no systems for managing the returns processes; A lack of a systems results in slow processing of the returns and the returned inventory; An inability to track or monitor inventory levels of returned stock; Few good channels exist to get value from their returned and processed units; Returns can be a significant problem if not managed well. 
Without good systems in place significant individual attention is often required to manage a single return to competition.

Outsource logistics providers or 3PRLs are ideally suited to help handle reverse logistics and generate significant savings since reverse logistics is an easy extension of the existing business services of 3PL operations: Many of your existing customers likely already need help; You are already masters at many of the required processes; You are experts at managing outsourced projects; You are experts at tracking and managing inventory; You are already doing minor inspection work; You are already doing minor reconditioning or repackaging; You are likely to generate significant savings in shipping; Your ability to rapidly process transactions solves their key problem of slow processing.

To be successful you need to satisfy the goals of your customer and the goals your company as the following Table 1:

Table1. Goals of Customers and Company

\begin{tabular}{|ll|ll|}
\hline \multicolumn{1}{|c|}{ Client Goals For 3PLs } & \multicolumn{1}{c|}{ Your Company Goals } \\
\hline - & Satisfy their customers & - & Smooth processes and workflow \\
- & Maximize asset recovery & - & Rapid inventory movement resulting in \\
- & Maximize returns processing speed & - & processing and transaction fees \\
- & Minimize processing costs \\
- & Minimize inventory levels \\
- & Monitor activity & Profitable fees for processing \\
- Monitor costs & - & High level of customer satisfaction \\
\hline
\end{tabular}

Outsourcing reverse logistics should be handled like other outsourcing decisions. The customers will be looking for: Cost savings - monthly costs, one time savings; Easy management; Regular status updates; One stop shopping - one provider who can handle as many of their requirements as possible; A partnership-the nature of returns will require a close working relationship.

Specific to reverse logistics handling clients will be looking for: Quality service for their customers -you may be an extension of your client's customer service group and will need to respond to their end customer's needs and requests; Rapid cycle time -through create, receive, ship or credit, inspect, recondition, recover; Accuracy correct handling of units through each step of the required processes; Inventory management and minimization - of both finished goods and good in process; No misplaced or unhandled units; Visibility -status of a unit or RMA at any given time; 
Timely data updates - i.e. to process customer credits based on receipts; Reports; Detailed billing.

In the U.S. and Europe, consumer goods firms generally outsource logistics needs to 3PLs. Although 3PLs control a small share of the overall logistics market in China, they are growing in importance for multinational companies and organizations looking to set up or expand operations in China. 3PLs are essentially supply chain managers who subcontract some of their logistics requirements to container lines, trucking firms and airfreight companies. Many own assets such as distribution centers, warehouses and trucking fleets, and a growing number of providers are expanding to offer across-the-board services. For consumer goods companies looking to move their product into or around China, outsourcing to a 3PL can mean lower supply chain costs.

According to Morgan Stanley \& Co. Incorporated reported in 2004, while 3PLs currently handle just $16 \%$ of final products in China, more foreign and local 3PLs will enter the market over the next five years (Storage Institute, 2005). The emerging 3PL industry in China may be categorized into four types: (1) Large SOEs (such as Sinotrans, COSCO and China Post) with extensive transport and warehousing assets, broad national networks, and strong relationships with central and provincial governments. These firms already enjoy a monopoly in several areas of trucking, shipping and postal services. (2) Medium-sized domestic logistics providers (generally privately owned), which focus on one or two key industries. (3) Logistics divisions of manufacturers and processors, primarily providing services to internal customers, but sometimes offering 3PL services to outside companies. The Shanghai Fruit Distribution Center is an example of a subsidiary company that has sought to internalize logistics needs. However, as an SOE, the division is struggling to update its facilities and compete with private counterparts. (4) Foreign logistics providers, including multinational firms, new wholly foreign owned entities (WFOEs) and smaller firms working in niche markets.

China's leading 3PLs are large foreign companies licensed to operate as WFOEs. Also growing in importance are foreign companies that are currently restricted to operating as joint-venture partners or through free-trade zones (FTZs). In 2001, the government of Shanghai's Pudong New Area lifted all restrictions on warehousing and logistics companies setting up operations in the Wai Gao Qiao Bonded Zone, equalizing their position with trading companies in the zone. Foreign companies are now allowed to operate these warehouses themselves to store a wide variety of raw materials, parts and other finished goods for onward sale and shipment into China. In Wai Gao Qiao, foreign operators generally maintain high-standard warehouses at their 
manufacturing facilities, which can double as regional distribution centers. A growing number of providers are "one-stop-shops" that offer wide-ranging import distribution services that extend beyond logistics. By 2006, all of these firms will be permitted to operate as WFOEs, and will be free to offer a wide array of services, provided they obtain the necessary licenses.

The current challenge for most companies is just getting a return fully processed, never mind effectively, inexpensively or in a timely manner. The management of reverse logistics is a painful process for manufacturers and retailers. It also represents a small part of their business and they are often not willing to commit the people, systems or resources to this area to manage it well. Few standards exist to define how to process and manage returns, but these processes are related to forward logistics processes. As a result, it is an easy extension of the existing 3PLs business, creating a lot of value for your customers. This translates into profits. Since there is room for improvement at your customers operations, the emphasis will be on organized delivery of good reverse logistics services, not on price.

While many 3PL's and outsource service providers claim to provide reverse logistics services, few are doing more than very basic receiving of a small volume of returned goods. There are several companies that have specialized in handling returned goods. Many of these companies appear to be very successful and growing.

\section{EVALUATION MODELS}

Since the complexity of reverse logistics, the evaluation for 3PRLs is difficult to be presented by the sole indicator, (i.e., if we want find the perfect synthesis evaluative system, the analysis based on the multi-angle and perspectives need to be considered). Therefore, the determinant indicator weights and the evaluation techniques become important considerations. They will decide if the overall evaluation models are excellent or bad.

Usually, the approaches for measuring the evaluating weights are involved in Analytic Hierarchy Process (AHP), Delphi, Entropy Value and Fuzzy Clustering Analysis, where the preceding two techniques are based on the experts' knowledge, experience and value judgment. For example, the quantitative analysis recur to AHP, however, the subjective shortage is inevitably; the Entropy technique estimate is based on the external characters of historical data, the presupposition needs sample data existing and is short of the compare to the landscape orientation, so there are limitation in application; the Fuzzy Analysis is based on comparability of the historical data to 
classify for the evaluating indicators. It is easy to see, integrating these methods may reduce abovementioned shortages by each.

Among the evaluating techniques, Technique for Order Preference by Similarity to Ideal Solution (TOPSIS) and Grey Relational Analysis (GRA) are all using by constructing the ideal solutions and the negative ideal solution for the indicators evaluative problem, and take two benchmarks as the estimation base of the evaluating objectives (i.e., the adjacent ideal solutions and the removed negative ideal solutions). The traditional TOPSIS is based on the Euclidean distance by way of measures just to reflect the data curve location, but it couldn't illustrate the data state change; the Grey Relational Analysis was used in the analogical degrees among curves to measure the correlation degree, which reflect the adjacent and removed degree of the curve geometrical comparability between the ideal solutions and the negative ideal solutions. Applying TOPSIS or Grey Relational Analysis respectively, that do nothing but calculates the solution optimization or not, then the results will be inadequate complete and impersonality, in this way, constructing the new nearness degree to reflect the location and the data curve comparability by combining with the Euclidean distance and the grey correlation degree.

In addition, the different indicators often have the various dimensions, so it is difficult to compare with those directly, the standardization processing for the initial decision-making matrix is necessary. Most of works were used to the linear transformation in $[0,1]$, which just consider award no penalty. Using the different standardization processing may result in the different evaluating results, however, based on the "awarding optimization penalizing bad" principle, combining with the linear operator to standardize the indicators data is utility. To reflect the manufacturer practical demand impersonally and indicate 3PRLs by any possibility faithfully, the integrating decisions making technique will be applied, and determining the evaluating weights using by AHP and the entropy value technique, the ideal solutions nearness degrees are calculated using by TOPSIS and the Grey Relational Analysis, thereby, the a perfect indicators evaluating model may be set up. Herein, we consider add two parameters $\alpha, \beta$ into the model by way of the elasticity factors, where $\alpha$ denotes the decision maker cognize the proportions between subjective and impersonal factors, $\beta$ reflect the decision maker considers nearness degrees for order preference based location and shape to add flexible monitoring and feasibility for decision making. To increasing the accuracy and practicability of the model, we need employ the linear transformation operator based on $[-1,1]$ to the standardization processing for the indicators data. 
The following evaluating model integrates with weight determined, indicator evaluated, standardized processing, elasticity factor etc., in this way, it is an integrated evaluating framework. Therefore, we can analyze all kinds of influencing factors for decision making in the round, and integrate the subjective experiences and the impersonal data, synthetically utilize the nearness degrees that reflected the similarity between distances and flexibility, and bring into play "awarding optimization and penalizing bad" advantages, such that the decision making calculating processes have substantial results in application and theory, and the results much more accuracy; otherwise, utilizing the elasticity factors will increase the agility for the model, and make for holding the evaluative keynote as a whole based on the manufacturer demands.

\subsection{Determined Evaluating Indicators Weights}

1) Utilizing AHP finds the indicator weights subjectively

Suppose that there exist $m$ selected solutions and $n$ evaluating indicators, according to experiences and the practice, the experts compared with those solutions, obtain the estimated matrix $A$ that figures the correlation significant degrees.

Calculating the eigenvector $P=\left(p_{j}\right)$ of $A$, where $p_{j}$ denotes the weighted value of indicator $j$.

\section{2) Consistency test}

The consistency of the judgment matrix is tested by the random consistency ration $C R, C R$ is more smaller, the consistency is more better. Based on Saaty's results, when $n>2$ and $C R \leq 0.1$, the judgment matrix will satisfy the consistency condition, where $C R=C I / R I$, and $C I=(\lambda-n) /(n-1), \lambda$ denotes the maximum eigenvalue, $R I$ change with the matrix order $n$, the changing value shown in Table 2.

Table 2. RI values

\begin{tabular}{|l|c|c|c|c|c|c|c|c|c|c|c|c|c|}
\hline $\mathrm{n}$ & 1 & 2 & 3 & 4 & 5 & 6 & 7 & 8 & 9 & 10 & 11 & 12 & 13 \\
\hline $\mathrm{RI}$ & 0.00 & 0.00 & 0.52 & 0.89 & 1.12 & 1.26 & 1.63 & 1.41 & 1.46 & 1.49 & 1.52 & 1.54 & 1.56 \\
\hline
\end{tabular}

3) Using the entropy value technique to analyze the impersonal data, calculating the evaluating indicator weights.

Let $X_{i j}$ denotes that $j$ indicator value of $i$ selected solution, the initial matrix presents as follows: 


$$
X=\left[\begin{array}{cccc}
x_{11} & x_{12} & \cdots & x_{1 n} \\
x_{21} & x_{22} & \cdots & x_{2 n} \\
\vdots & \vdots & \vdots & \vdots \\
x_{m 1} & x_{m 2} & \cdots & x_{m n}
\end{array}\right], i \in[1, m], j \in[1, n]
$$

Considering the different indicators have the different dimensions, however, the indicator cannot be negative value for the entropy value, here the standardization processing is used by the normalized technique:

$$
Y=\left\{y_{i j}\right\}_{m \times n}, y_{i j}=\frac{x_{i j}}{\sum_{i=1}^{m} x_{i j}}
$$

Then, the entropy value of $j$ item indicator based on $Y_{i j}$ can be written as:

$$
e_{j}=-k \sum_{i=1}^{m} y_{i j} \ln y_{i j}
$$

where $k$ is a constant relative to $m, k=(\ln m)^{-1}$.

Information available value of the indicator rests with the difference value $h_{j}$ between its entropy value $e_{j}$ and 1 , i.e.,

$$
h_{j}=1-e_{j}
$$

then, the weight of $j$ item indicator is provided with:

$$
q_{j}=\frac{h_{j}}{\sum_{j=1}^{n} h_{j}}
$$

4) Adding the elasticity factor $\alpha$, we can gain the final indicator weight $W_{i}$ based on combined the subjective value and the impersonal value:

$$
W_{i}=\alpha_{1} p_{i}+\alpha_{2} q_{i}, \quad 0 \leq \alpha_{1}, \alpha_{2} \leq 1, \quad \alpha_{1}+\alpha_{2}=1
$$

where $\alpha_{1}$ and $\alpha_{2}$ show that the decision maker reckon the proportions based on the effect of subjective factors and the impersonal factors, respectively, those data need given during calculation. 


\subsection{Evaluating Approach Integrated with the Traditional TOPSIS and Grey}

\section{Relative Analysis}

1) Applied the linear transform operator on $[-1,1]$ to deal with the initial data, set up the normalized matrix $Z$.

First, calculates the contracted value $x_{0 j}$ :

$$
x_{0 j}=\frac{1}{m} \sum_{i=1}^{m} x_{i j}
$$

if $j$ indicator is a benefit indicator, its value more is, and better for results, then:

$$
Z_{i j}=\frac{x_{i j}-x_{0 j}}{\max \left(\max _{i} x_{i j}-x_{0 j}, x_{0 j}-\min _{i} x_{i j}\right)}
$$

if $j$ indicator is a cost indicator, its value smaller is, and better for results, then:

$$
Z_{i j}=\frac{x_{0 j}-x_{i j}}{\max \left(\max _{i} x_{i j}-x_{0 j}, x_{0 j}-\min _{i} x_{i j}\right)}
$$

2) Constructing the weighted normalized matrix $V$ is as follows:

$$
V=\left[\begin{array}{cccc}
w_{1} z_{11} & w_{2} z_{12} & \cdots & w_{n} z_{1 n} \\
w_{1} z_{21} & w_{2} z_{22} & \cdots & w_{n} z_{2 n} \\
\vdots & \vdots & \vdots & \vdots \\
w_{1} z_{m 1} & w_{2} z_{m 2} & \cdots & w_{n} z_{m n}
\end{array}\right]=\left[\begin{array}{cccc}
v_{11} & v_{12} & \cdots & v_{1 n} \\
v_{21} & v_{22} & \cdots & v_{2 n} \\
\vdots & \vdots & \vdots & \vdots \\
v_{m 1} & v_{m 2} & \cdots & v_{m n}
\end{array}\right]
$$

3) Find the ideal solution $V_{0 j}^{+}$and the negative ideal solution $V_{0 j}^{-}$such that:

$$
\begin{aligned}
& V_{0 j}^{+}=\max _{i} v_{i j} \\
& V_{0 j}^{-}=\min _{i} v_{i j}
\end{aligned}
$$


4) Compute the Euclidean distances $S_{i}^{+}$and $S_{i}^{-}$from $i$ selected solution to the ideal solution and the negative ideal solution, respectively:

$$
\begin{aligned}
& S_{i}^{+}=\sqrt{\sum_{j=1}^{n}\left(v_{i j}-v_{0 j}^{+}\right)^{2}} \\
& S_{i}^{-}=\sqrt{\sum_{j=1}^{n}\left(v_{i j}-v_{0 j}^{-}\right)^{2}}
\end{aligned}
$$

5) Compute the grey correlation degrees $R_{i}^{+}$and $R_{i}^{-}$from $i$ selected solution to the ideal solution and the negative ideal solution, respectively.

According to the grey relative coefficient $r_{i j}^{+}$computed based on $i$ solution and the ideal solution for $j$ indicator, establishing the grey relative coefficient matrix $R^{+}$satisfy:

$$
R^{+}=\left\{r_{i j}^{+}\right\}_{m \times n}, \quad r_{i j}^{+}=\frac{\min _{i} \min _{j}\left|v_{0 j}^{+}-v_{i j}\right|+\zeta \max _{i} \max _{j}\left|v_{0 j}^{+}-v_{i j}\right|}{\left|v_{0 j}^{+}-v_{i j}\right|+\zeta \max _{i} \max _{j}\left|v_{0 j}^{+}-v_{i j}\right|}, \quad \zeta \in(0,1)
$$

where $\zeta$ is a distinguishing coefficient, often given 0.5 .

Thus, the grey correlation degree based on $i$ solution and the ideal solution meets:

$$
R_{i}^{+}=\frac{1}{n} \sum_{j=1}^{n} r_{i j}^{+}
$$

and the grey correlation degree based on $i$ solution and the negative ideal solution satisfes:

$$
\begin{gathered}
R^{-}=\left\{r_{i j}^{-}\right\}_{m \times n}, r_{i j}^{-}=\frac{\min _{i} \min _{j}\left|v_{i j}-v_{i j}^{-}\right|+\zeta \max _{i} \max _{j}\left|v_{i j}-v_{i j}^{-}\right|}{\left|v_{i j}-v_{i j}^{-}\right|+\zeta \max _{i} \max _{j}\left|v_{i j}-v_{i j}^{-}\right|}, \zeta \in(0,1) \\
R_{i}^{-}=\frac{1}{n} \sum_{j=1}^{n} r_{i j}^{-}
\end{gathered}
$$


6) Applying the linear transform operator defined on $[-1,1]$ to $S_{i}^{+} 、 S_{i}^{-} 、 R_{i}^{+} 、 R_{i}^{-}$, we can obtain the normalized matrix $C$.

First, compute the odds ratio for lines

$$
\begin{aligned}
& S_{0}^{+}=\frac{1}{m} \sum_{i=1}^{m} S_{i}^{+} \\
& S_{0}^{-}=\frac{1}{m} \sum_{i=1}^{m} S_{i}^{-} \\
& R_{0}^{+}=\frac{1}{m} \sum_{i=1}^{m} R_{i}^{+} \\
& R_{0}^{-}=\frac{1}{m} \sum_{i=1}^{m} R_{i}^{-}
\end{aligned}
$$

If $S_{i}^{-}$and $R_{i}^{+}$are more bigger, the solution is more close to the ideal solution. Under this case, the indicator may be seen the beneficial indicator, then

$$
\begin{aligned}
c_{i 2} & =\frac{S_{i}^{-}-S_{0}^{-}}{\max \left(\max S_{i}^{-}-S_{0}^{-}, S_{0}^{-}-\min S_{i}^{-}\right)} \\
c_{i 3} & =\frac{R_{i}^{+}-R_{0}^{+}}{\max \left(\max R_{i}^{+}-R_{0}^{+}, R_{0}^{+}-\min R_{i}^{+}\right)}
\end{aligned}
$$

Considering that when $S_{i}^{+}$and $R_{i}^{-}$are more smaller, the solution is more closed to the ideal solution, it can be seen the cost indicator, then:

$$
\begin{aligned}
c_{i 1} & =\frac{S_{0}^{+}-S_{i}^{+}}{\max \left(\max S_{i}^{+}-S_{0}^{+}, S_{0}^{+}-\min S_{i}^{+}\right)} \\
c_{i 4} & =\frac{R_{0}^{-}-R_{i}^{-}}{\max \left(\max R_{i}^{-}-R_{0}^{-}, R_{0}^{-}-\min R_{i}^{-}\right)}
\end{aligned}
$$

and the decision-making matrix $C$ based on the relative nearness degrees follows:

$$
C=\left\{c_{i j}\right\}_{m \times 4}
$$


7) Adding the elastic factor $\beta$, the final decision making $C_{i}$ based on the relative nearness degrees is given:

$$
C_{i}=\beta_{1}\left(c_{i 1}+c_{i 2}\right)+\beta_{2}\left(c_{i 3}+c_{i 4}\right), \quad 0 \leq \beta_{1}, \beta_{2} \leq 1, \quad \beta_{1}+\beta_{2}=1
$$

where $\beta_{1}$ and $\beta_{2}$ stand for the preference degrees relative to location and shape, respectively, the detailed data are given by the decision maker.

In the light of the amount of the relative nearness degree, we can determine the order preference for the selected solutions. The optimization or bad of the selected solutions is shown by the amounts.

\section{CASE STUDY}

To further illustrate the practicability and feasibility of the model, a case for the Great Wall 3PRLs Co. is considered in this section. From the manufacturers' viewpoints, the evaluating analysis of 3PRLs can be considered those aspects involving in managing level, information monitoring, vehicle types, network overlay, craft brother experience and expense etc. Using by Matlab7.0 and the abovementioned evaluating model, the order preference for the 3PRLs will be obtained.

The relative significant matrix $A$ based the initial data follows:

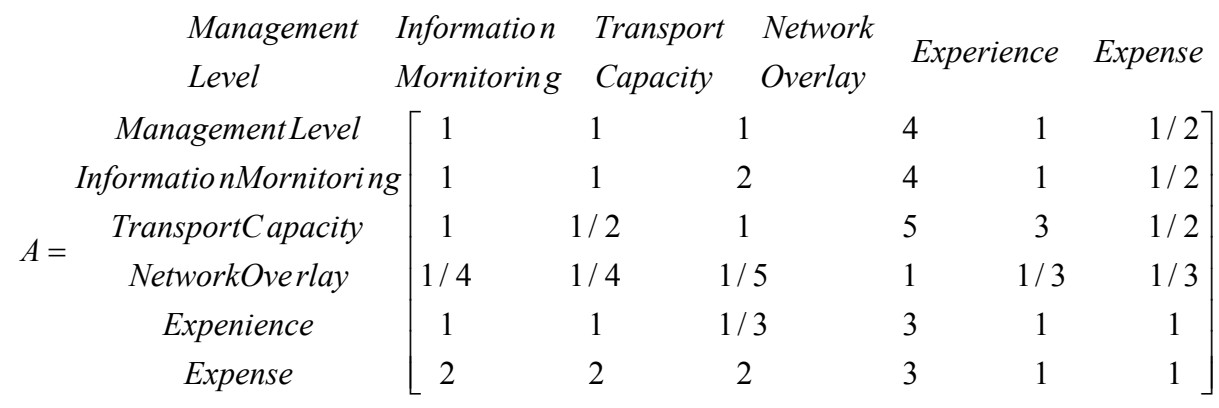

Based on AHP, the weights of the evaluating indicators have the following form: $P_{i}=(0.1584,0.1893,0.1980,0.0483,0.1503,0.2558)$, and the maximum eigenvalue $\lambda=6.4203$.

The initial data of all indicators based on selected service providers are shown in Table 3. Using by the normalized technique and the entropy value technique, the evaluating indicators weights follows: $Q_{i}=(0.2216,0.1460,0.0448,0.1688,0.0047,0.4141)$. 
Table 3. The original data for the 3PRLs indicators

\begin{tabular}{c|c|c|c|c|c|c}
\hline IPRLs & $\begin{array}{c}\text { Management } \\
\text { Level }\end{array}$ & $\begin{array}{c}\text { Information } \\
\text { monitoring } \\
\text { Ability }\end{array}$ & $\begin{array}{c}\text { Transportation } \\
\text { Capacity }\end{array}$ & $\begin{array}{c}\text { Network } \\
\text { Overlay }\end{array}$ & Experience & $\begin{array}{c}\text { Expense } \\
\text { (\$Thousand) }\end{array}$ \\
\hline \hline A & 0.6500 & 0.2300 & 0.8600 & 0.1700 & 0.9705 & 35.0500 \\
B & 0.3300 & 0.1300 & 0.7800 & 0.2300 & 0.9316 & 40.0300 \\
C & 0.5100 & 0.2100 & 0.8900 & 0.1500 & 0.9009 & 50.0300 \\
D & 0.6800 & 0.1600 & 0.6500 & 0.1600 & 0.9484 & 20.0200 \\
E & 0.4500 & 0.1600 & 0.8800 & 0.2600 & 0.9911 & 50.0600 \\
F & 0.5000 & 0.1800 & 0.7900 & 0.1900 & 0.9106 & 60.0800 \\
\hline
\end{tabular}

Suppose that the decision-maker identify proportions account for the subjective factors and impersonality factors relative to the indicator weights, i.e., $\alpha_{1}=0.4$, $\alpha_{2}=0.6$, respectively. From (6), the final indicator weight is

$$
W_{i}=(0.1963,0.1633,0.1061,0.1206,0.0629,0.3508)
$$

and the consistency test shows that $C I=0.0841$, and $C R=0.0667<0.1$.

Applying the linear transform operator on $[-1,1]$ to the initial data, the normalized matrix $U$ follows:

$$
U=\left[\begin{array}{cccccc}
0.6842 & 1.0000 & 0.3263 & -0.3500 & 0.5789 & 0.3327 \\
-1.0000 & -0.9355 & -0.1789 & 0.5500 & -0.2164 & 0.1117 \\
-0.0526 & 0.6129 & 0.5158 & -0.6500 & -0.8440 & -0.3323 \\
0.8421 & -0.3548 & -1.0000 & -0.5000 & 0.1271 & 1.0000 \\
-0.3684 & -0.3548 & 0.4526 & 1.0000 & 1.0000 & -0.3336 \\
-0.1053 & 0.0323 & -0.1158 & -0.0500 & -0.6457 & -0.7785
\end{array}\right]
$$

From (10), constructing the weighted normalized matrix $V$ is as follows:

$$
V=\left[\begin{array}{cccccc}
0.1343 & 0.1633 & 0.0346 & -0.0422 & 0.0364 & 0.1167 \\
-0.1963 & -0.1527 & -0.0190 & 0.0663 & -0.0136 & 0.0392 \\
-0.0103 & 0.1001 & 0.0547 & -0.0784 & -0.0531 & -0.1166 \\
0.1653 & -0.0579 & -0.1061 & -0.0603 & 0.0080 & 0.3508 \\
-0.0723 & -0.0579 & 0.0480 & 0.1206 & 0.0629 & -0.1170 \\
-0.0207 & 0.0053 & -0.0123 & -0.0060 & -0.0406 & -0.2731
\end{array}\right]
$$


From (11), (12), we can deduce the ideal solution $V_{i}^{+}$and the negative ideal solution $V_{i}^{-}$

$$
\begin{aligned}
& V_{i}^{+}=(0.1653,0.1633,0.0547,0.1206,0.0629,0.3508), \\
& V_{i}^{-}=(-0.1963,-0.1527,-0.1061,-0.0784,-0.0531,-0.2731)
\end{aligned}
$$

Computing the Euclidean distances $S_{i}^{+}$and $S_{i}^{-}$from the selected solution to the ideal solution and the negative ideal solution, respectively,

$$
\begin{aligned}
& S_{i}^{+}=(0.2887,0.5848,0.5534,0.3325,0.5695,0.6928) \\
& S_{i}^{-}=(0.6247,0.3572,0.3858,0.7301,0.3543,0.2646)
\end{aligned}
$$

Thus, we can represent the grey relative degrees $R_{i}^{+}$and $R_{i}^{-}$from the selected solution to the ideal solutions and the negative ideal solutions, respectively

$$
\begin{aligned}
& R_{i}^{+}=(0.8332,0.6539,0.7018,0.7880,0.7553,0.6514) \\
& R_{i}^{-}=(0.6315,0.8087,0.7507,0.7241,0.6929,0.8076)
\end{aligned}
$$

Suppose that the order preference based on the decision-maker selected the location and shape, respectively, i.e., $\beta_{1}=0.7, \beta_{2}=0.3$, then the final decision-making vector for the relative nearness degree $C_{i}$ follows

$$
C_{i}=(1.7340,-0.9390,-0.4581,1.4592,-0.2675,-1.5286)
$$

According to the nearness degrees we can size that $A \succ D \succ E \succ C \succ B \succ F$, and this shows the $A$ is the optimum choice of the manufacturer under the known conditions, next one is $D$. From the numerical value results based on added the two elasticity factors $\alpha$ and $\beta$ in the model, in this way, we can improve participant of the decision-makers, and decision-making is more accordance with the physical background and increase the flexibility for the model. Table 4 reveals that the results under the different $\alpha$ and $\beta$.

In a general way, the different $\alpha$ and $\beta$ selected have an immediate effect on the decision-making of the manufacturer. Therefore, the decision-makers can be based on their preference to choose the parameters of $\alpha$ and $\beta$, and the problem can be regarded as the group decision-making problem based on the participators. 
Table 4. The contrasting order results under the different factors

\begin{tabular}{|c|c|c|c|}
\hline & Compared Weights & & Results \\
\hline$\alpha_{1}=0.3 ; \alpha_{2}=0.7$ & $6 \succ 1 \succ 2 \succ 4 \succ 3 \succ 5$ & $\beta_{1}=0.3 ; \beta_{2}=0.7$ & $A \succ D \succ E \succ C \succ B \succ F$ \\
\hline 1 & 0.2026 & A & 1.8860 \\
\hline 2 & 0.1589 & B & -1.2276 \\
\hline 3 & 0.0908 & $\mathrm{C}$ & -0.4379 \\
\hline 4 & 0.1327 & $\mathrm{D}$ & 1.0098 \\
\hline 5 & 0.0484 & E & 0.2579 \\
\hline 6 & 0.3666 & $\mathrm{~F}$ & -1.4881 \\
\hline$\alpha_{1}=0.5 ; \alpha_{2}=0.5$ & $6 \succ 1 \succ 2 \succ 3 \succ 4 \succ 5$ & $\beta_{1}=0.5 ; \beta_{2}=0.5$ & $A \succ D \succ E \succ C \succ B \succ F$ \\
\hline 1 & 0.1900 & A & 1.8100 \\
\hline 2 & 0.1676 & B & -1.0833 \\
\hline 3 & 0.1214 & $\mathrm{C}$ & -0.4480 \\
\hline 4 & 0.1086 & $\mathrm{D}$ & 1.2345 \\
\hline 5 & 0.0775 & $\mathrm{E}$ & 0.0048 \\
\hline 6 & 0.3349 & $\mathrm{~F}$ & -1.5084 \\
\hline$\alpha_{1}=0.7 ; \alpha_{2}=0.3$ & $6 \succ 1 \succ 2 \succ 3 \succ 5 \succ 4$ & $\beta_{1}=0.7 ; \beta_{2}=0.3$ & $A \succ D \succ E \succ C \succ B \succ F$ \\
\hline 1 & 0.1774 & A & 1.7340 \\
\hline 2 & 0.1763 & B & -0.9390 \\
\hline 3 & 0.1520 & $\mathrm{C}$ & -0.4581 \\
\hline 4 & 0.0845 & $\mathrm{D}$ & 1.4592 \\
\hline 5 & 0.1066 & $\mathrm{E}$ & -0.2675 \\
\hline 6 & 0.3033 & $\mathrm{~F}$ & -1.5286 \\
\hline
\end{tabular}

Notes: 1 Management Level; 2 Information Monitoring Ability; 3 Transportation Capacity; 4 Network Overlay; 5 Experience; 6 Expense

\section{CONCLUSIONS}

The feasibility and desirability of reverse logistics in market-motivated contexts are examined based on the China current in this paper. The interactions among the major barriers, which hinder or prevent the application of reverse logistics in China were analyzed. A key task of top management is to diagnose those barriers of reverse logistics that could be crucial to the survival of the organization in the future. Simultaneity, a value delivery system exists to create value for customers and environments by supplying needed products and services. Value delivery systems are at the heart of every firm and, more than anything else, determine whether the firm 
survives in the marketplace or disappear into bankruptcy or takeover. The processes and model of market-motivated reverse logistics value delivery system are discussed in this paper, and the processes content and model are presented. At the same time, based on the advantage of the third party reverse logistics providers (3PRLs) and outsourced service providers, an integrated evaluation model was built to select the three reverse logistics service providers using by the integrating decision-making methods in this paper. To reflect the comprehensive information, the Analytic Hierarchy Process and entropy approaches are applied to calculate the objective weights. A new kind of relative similarity degree was established by combining the Euclidean distance with the grey correlation degree. In the end, an example was demonstrated our conclusions.

\section{REFERENCES}

Appa, G.M. and Giannikos, I., 1994, "Is Linear Programming Necessary for Single Facility Location with Maximin of Rectilinear Distance?," Journal of the Operational Research Society, 45 (1), 97-107.

Barros, A. I, Dekker, R. and Scholten, V., 1998, “A Two-level Network for Recycling Sand: A Case Study," European Journal of Operational Research, 110 (2), 199-214.

Brandeau, M. L. and Chin, S. S., 1989, “An Overview of Representative Problems in Pocational Research," Management Science, 35 (6), 645-667.

Cairncross, F., 1992, Costing the Earth, Harvard Business School Press, Boston, MA.

Chen, Meifang and Tzeng, Gwo- Hshiung, 2004, "Combining Grey Relation and TOPSIS Concepts for Selecting an Expatriate Host Country," Mathematical and Computer Modelling, 40(13) 1473-1790.

Chitu Okoli and Pawlowski S. D., 2004, "The Delphi Method as a Research Tool: an Example, Design Considerations and Applications," Information \& Management, 42(1), 15-29.

Cooper, W.W., Gallegos, A. and Granor, M. H., 1995, “A Delphi Study of Goals and Evaluation Criteria of State and Privately Owned Latin American Airlines," Socio-Economic Planning Sciences, 29(4), 273-285.

Corbett, C. J and Kleidorfer, P. R., 2001, "Environmental Management and Operations Management: Introduction to Part I (Manufacturing and Eco-logistics)," Production and Operations Management, 10 (2), 107-111.

Daugherty, P.J., Myers, M.B. and Richey, R.G., 2002, "Information Support for 
Reverse Logistics: the Influence of Relationship Commitment," Journal of Business Logistics, 23 (1), 85-106.

de Brito, M. P. and Dekker, R., 2003, "Modelling Product Returns in Inventory Control - Exploring the Validity of General Assumptions," International Journal of Production Economics, 81-82, 225-241.

de Brito, M.P., Flapper, S.D.P. and Dekker, R., Reverse Logistics: A Review of Case Studies, Econometric Institute Report EI 2002-21. Available at http://www. eur.nl/WebDOC/doc/econometrie/feweco20020605160859.pdf (accessed 2002).

Deng Hepu, Yeh Chung-Hsing and Willis, R. J., 2000, "Inter - Company Comparison Using Modified TOPSIS with Objective Weights," Computers and Operations Research, 27(10), 963-973.

Duff and Ortega, 1995, "How Wal-Mart Outdid a Once-touted K-Mart in Discount-store Race,” Wall Street Journal, March 24.

Fleischmann, M., Beullens, P., Bloemhof-Ruwaard, J. M. and Wassenhove, L. N. V., 2001, "The Impact of Product Recovery on Logistics Network Design," Production \& Operations Management, 10 (2), 156-173.

Fleischmann, M., Krikke, H. R., Dekker, R. and Flapper, S.D.P., 2000, "A Characterization of Logistics Networks for Product Recovery,” Omega, 28 (6), 653-666.

Fleischmann, M., Wassenhove, L. N. V. , van Nunen, J. A. E. E., van der Laan, E., Dekker, R. and Bloemhof-Ruwaard, J. M., 1997, "Quantitative Models for Reverse Logistics: A Review," European Journal of Operational Research, 103 (1), 1-17.

Frosch, R.A., 1995, "Industrial Ecology: Adapting Technology for a Sustainable World," Environment, 37 (10), 16-37.

Giannikos, I., 1998, “A Multi-objective Programming Model for Locating Treatment Sites and Routing Hazardous Wastes," European Journal of Operational Research, 104 (2), 333-342.

Gibson, 1995, “At McDonald's New Receipts for Buns, Eggs,” Wall Street Journal, June 13.

Giorgiadis, P. and Vlachos, D., 2003, "The Effect of Environmental Parameters on Product Recovery," Article in Press, European Journal of Operational Research, 105 (3), 234-239.

Guide Jr., V. D. R., Jayraman, V. and Linton, J. D., 2003, "Building Contingency Planning for Closed-loop Supply Chains with Product Recovery," Journal of Operations Management, 21 (3), 259-279. 
Guintini, R. and Andel, T., 1995, “Advance in Reverse Logistics: Part 1," Transp. Distrib. 36 (2), 73-77.

Guojun Ji, 2005, "Logistics and Matter Element Models on the Firm's Innovative Approach," Journal of International Logistics and Trade, 3(1), 121-145.

Hill, T., 2000, Manufacturing strategy: Text and cases, $3^{\text {rd }}$ edition, Irwin.

Harrington, J., 1991, Business Process Improvement, McGraw-Hill.

I. Maslennikova and Foley, D., 2000, "Xerox's Approach to Sustainability," Interfaces, 30 (3), 226-233.

Jayaraman, V., Guide, V. D. R. and Srivastava, R., 1999, “A Closed-loop Logistics Model for Remanufacturing," Journal of the Operational Research Society, 50 (5), 497-508.

Kostecki, M. (ed.), 1998, The Durable Use of Consumer Products: Options for Business and Consumption, Kluwer Academic Press, Dordsedet.

Krumwiede, D. W. and Sheu, C., 2002, "A Model for Reverse Logistics Entry by Third-party Providers," Omega, 30 (5), 322-333.

Landers, T.L., Cole, M.H., Walker, B. and Kirk, R.W., 2000, "The Virtual Warehousing Concept," Transportation Research Part E. 36 (2), 115-125.

Liang, G. C., Zheng, Y. P. and Pu, H. B., 2004, "Grey Relation Analysis of Optimized Design for Underground Gas Storage,” Natural Gas Industry, 24(9), 142-144.

Lindhqvist, T., 2000, Extended Producer Responsibility in Cleaner Production; Policy Principle to Promote Environmental Improvements of Product Systems, Un-published $\mathrm{PhD}$ thesis, Lund University, Sweden.

Meade, L. and Sarkis, J., 2002, “A Conceptual Model for Selecting and Evaluating Third-party Reverse Logistics Providers," Supply Chain Management: An International Journal, 7 (5), 283-295.

Meredith and Shafer, 1999, Operations Management for MBA's, Wiley.

Meyer, H., 1999, "Many Happy Returns," The Journal of Business Strategy, 20 (4), 27-31.

Minner, S., 2003, "Reverse Logistics Inventory Models," International Journal of Production Economics, 81-82, 265-279.

Mok, H. S., Kim, H. J. and Moon, K.S., 1997, "Disassemblability of Mechanical Parts in Automobile for Recycling," Comput. Ind. Eng. 33 (3-4), 621-624.

Nagel, C. and Meyer, P., 1999, "Caught between Ecology and Economy: End-of-life Aspects of Environmentally Conscious Manufacturing," Computers \& Industrial Engineering, 36 (4), 781-792.

Nasr, N., 1997, "Environmentally Conscious Manufacturing," Careers and the 
Engineer, 26-27.

Owen, J.V., 1993, “Environmentally Conscious Manufacturing," Manufacturing Engineering, October, 44-55.

Pugh, M. P., 1993, "The Use of Mathematical Models in Evaluating Resource Recovery Options," Resources, Conservation \& Recycling, 8, 91-101.

Pushchak, R. and Rocha, C., 1998, "Failing to Site Hazardous Waste Facilities Voluntarily: Implications for the Production of Sustainable Goods," Journal of Environmental Planning and Management, 41 (1), 25-43.

Rogers, D.S. and Tibben-Lembke, R.S. 1998, Going Backwards: Reverse Logistics Trends and Practices, Reverse Logistics Executive Council, Pittsburgh, PA.

Rogers, D. and Tibben-Lembke, R.S., 1999, Going Backwards: Reverse Logistics Trends and Practices, RLEC Press, Pittsburgh.

Saaty, T.L., 1980, The Analytic Hierarchy Process, McGraw - Hill, New York.

Schmenner, R.W., 1982, Making Business Location Decisions, Prentice-Hall, Englewood Cliffs, New Jersey.

Shih, L., 2001, "Reverse Logistics System Planning for Recycling Electrical Appliances and Computers in Taiwan," Resources, Conservation and Recycling, 32 (1), 55-72.

Spengler, T., Püchert, H., Penkuhn T. and Rentz, O., 1997, "Environmental Integrated Production and Recycling Management," European Journal of Operational Research, 97 (2), 308-326.

Srinivasan, P. (ed.), 1999, Indian Distance Guide, TTK Pharma Ltd. Chennai, India.

Srivastava, S. K. and Srivastava, R. K., 2004, "Managing Product Returns for Reverse Logistics," forthcoming in International Journal of Physical Distribution and Logistics Management (special issue on Reverse Logistics).

The Fifth Logistics Report by the Storage Institute, China: Beijing, 2005.

Thierry, M., Salomon, V.J., Nunen, J.A.E.E Wassenhove, L.N.V., 1995, "Strategic Issues in Product Recovery Management," California Management Review, 37, 114-135.

Tibben-Lembke, R.S. and Rogers, D.S., 2002, "Differences between Forward and Reverse Logistics in a Retail Environment," International Journal of Supply Chain Management, 7(5), 271-282.

Van Hoek, R.I., 1999, "From Reverse Logistics to Green Supply Chains," International Journal of Supply Chain Management, 4 (3), 129-134.

WSRA, Business Recycling Roundtable Tukwila Washington minutes. Available at http://www.wsra.net/pdf/Minutes\%201-12-01.doc (accessed January 12, 2001). 
Xu, Z. S. and Wei, C. P. 1999, "A Consistency Improving Method in the Analytic Hierarchy Process," European Journal of Operational Research, 116(2), 443 -449 .

http://www. indiastat.com/

http://www.mapsofindia.com/roads/index.html 